\title{
Piel Virtual: Investigación Educativa Basada en Artes e Imagen Virtual
}

\author{
Virtual Skin: Arts-based Educational Research and Virtual Image
}

Antonio González-Torre

artesvisuales3d@gmail.com

\section{Joaquín Javier Roldán Ramírez}

kuakin@gmail.com

Universidad de Granada (España)
Recibido 14/09/2020 Revisado 12/10/2020

Aceptado 15/10/2020 Publicado 31/10/2020

\section{Resumen:}

"Piel Virtual" es un taller educativo en Artes Visuales que utiliza la imagen virtual desde un enfoque a/r/tográfico. Utilizamos el video mapping sobre la piel humana para indagar las múltiples posibilidades creativas, artísticas y pedagógicas que tienen los entornos virtuales como espacios de creación de imágenes.

En toda actividad artística hay un propósito investigador siempre que se tenga en cuenta el factor de creación que implican (Muntané, M. D. C. G., Hernández, F. H., \& López, H. J. P. (2006). Aunque dichos procesos y propósitos investigacionales necesitan un ámbito de difusión y unos modelos convencionales de formulación y difusión para permitir la actividad crítica y su validación por la comunidad académica. Biggs, M. (2003).

En nuestro taller de creación hemos trabajado a partir del trabajo del fotógrafo Daniel Oliver. Sus obras son fotografías de cuerpos con diversas formas de proyección lumínica. Se trata de fotografías que muestran volúmenes, formas, contornos anatómicos combinados con los múltiples efectos ópticos producidos por la luz y las imágenes que proyecta sobre los cuerpos. Se mezclan, así, volúmenes naturales con pieles virtuales, creando una sensación de profundidad sobre la piel y generando diálogos entre la luz que ilumina la escena y la luz que procede de las imágenes proyectadas. Los resultados de la práctica artística se muestran en forma de fotoensayos o de videocreaciones.

Por estos juegos y combinaciones, en la obra de Oliver, la imagen virtual es una herramienta de enorme versatilidad en la que lo digital se convierte en virtual.

El uso creativo de la imagen virtual a través TICs que giran en torno a las tecnologías de almacenamiento, procesamiento, recuperación y comunicación de la información a través de diferentes dispositivos electrónicos e informáticos. Belloch, C. (2012) asequibles en las aulas de Educación Artística ayudan en la construcción de metodologías que permiten a través de la experimentación fotografía, la videocreación y uso de plataformas digitales un encuentro fértil de enorme valor estético. Prácticas novedoras que desarrollan un diálogo a través de la luz, los espacios y el mensaje como un fin del medio.

Sugerencias para citar este artículo,

González Torre, A, Roldán, J (2020). Piel Virtual: Investigación Educativa Basada en Artes e Imagen Virtual. Tercio Creciente (Monográfico extraordinario II), págs. 115-124, https://dx.doi.org/10.17561/rtc.extra2.5750

GONZÁLEZ TORRE, A, ROLDÁN, J. Piel Virtual: Investigación Educativa Basada en Artes e Imagen Virtual. Tercio Creciente (Monográfico extraordinario II), octubre 2020, pp. 115-124, https://dx.doi.org/10.17561/rtc.extra2.5750 
Revista de Estudios en Sociedad, Artes y Gestión Cultural

\section{Abstract:}

"Virtual Skin" is an educational workshop in Visual Arts that uses the virtual image from an $\mathrm{a} / \mathrm{r} /$ tografic approach. We work with video mapping on human skin to investigate the multiple creative, artistic and pedagogical possibilities that virtual environments have as spaces for the creation of images.

In every artistic activity there is a research purpose as long as the creation factor involved is taken into account (Muntané, M. D. C. G., Hernández, F. H., \& López, H. J. P. (2006). Although such research processes and purposes need a scope of dissemination and conventional models of formulation and dissemination to allow critical activity and its validation by the academic community. Biggs, M. (2003).

In our creation workshop we have worked from the work of the photographer Daniel Oliver. His works are photographs of bodies with different forms of light projection. These are photographs that show volumes, shapes, anatomical contours combined with the multiple optical effects produced by light and the images it projects on the bodies. Thus, natural volumes are mixed with virtual skins, creating a sensation of depth on the skin and generating dialogues between the light that illuminates the scene and the light that comes from the projected images. The results of the artistic practice are shown in the form of photo essays or video creations.

Because of these games and combinations, in Oliver's work, the virtual image is a tool of enormous versatility in which the digital becomes virtual.

The creative use of the virtual image through ICTs that revolve around the technologies of storing, processing, recovering and communicating information through different electronic and computer devices. Belloch, C. (2012) affordable in the classrooms of Art Education help in the construction of methodologies that allow through photography experimentation, video creation and use of digital platforms a fertile encounter of enormous aesthetic value. Innovative practices that develop a dialogue through light, spaces and the message as an end of the medium.

\section{Palabras Clave: Imagen virtual, Video-mapping, Artes visuales}

Key words: Virtual image, video-mapping, visual arts

Sugerencias para citar este artículo,

González Torre, A, Roldán, J (2020). Piel Virtual: Investigación Educativa Basada en Artes e Imagen Virtual. Tercio Creciente (Monográfico extraordinario II), págs. 115-124, https://dx.doi.org/10.17561/rtc.extra2.5750

GONZÁLEZ TORRE, A, ROLDÁN, J. Piel Virtual: Investigación Educativa Basada en Artes e Imagen Virtual. Tercio Creciente (Monográfico extraordinario II), octubre 2020, pp. 115-124, https://dx.doi.org/10.17561/rtc.extra2.5750 


\section{Contexto}

La propuesta educativa se desarrollo en el marco taller monográfico de Artes Visuales aplicadas a las Artes escénicas realizado en la Escuela de Artes Escénicas "Body Wave" durante el año 2017 en el mes de Mayo, con el objetivo de la realización de contenido audiovisual para la obra de teatro de carácter anual denominada "FEMME". El acto escénico se realiza como muestra de graduación anual de los miembros de la escuela y con el apoyo del Excmo. Ayuntamiento de Jaén y el patronato de deportes de la localidad. Los resultados visuales del taller corresponden al marco de la enseñanza, aprendizaje y creación de contenido artístico a partir del material obtenido gracias al uso de la imagen virtual y fotografías realizadas por los participantes del taller. Como objetivo se trabajó conceptos relacionados con la creación y manipulación de imágenes virtuales mediante tecnologías y plataformas digitales para posteriormente hacer uso de las proyecciones mediante la técnica Video-Mapping Corporal.

La técnica Video-Mapping Corporal consiste en la utilización de tecnologías de proyección sobre superficies en los cuales se proyecta una virtualidad, video, animación o imagen; agregando una dimensión extra al objeto real y generando una ilusión óptica dinámica sobre el mismo. El uso de la tecnología se clasifica como una "herramienta" y como un "medio" cartografiando el espacio y creando un entorno virtual de imágenes mediante la combinación de elementos audiovisuales.Es precisamente su carácter multidisciplinar e impreciso donde radica su mayor atractivo.

La práctica a través de la luz trata de desvelar la doble dimensión de una imagen virtual y ayuda a crear un entorno adecuado para entender sus posibilidades. Lo más interesante es que en esta búsqueda de una dimensión paralela entre cuerpo y la imagen, la producción y elaboración del taller ayuda a potenciar el aprendizaje de ciertos conocimientos necesarios para entender diferentes tecnologías que intervienen en los procesos de producción. La creación de estas imágenes busca un abordaje creativo y resolutivo de los problemas existentes que intervienen entre medios de proyección y el contenido virtual. Siempre ensalzando la imagen de cuerpos que se constituyen en el espacio real mediante la "Luz" y creando un contenido visual que justifica esta puesta en práctica. Con la ayuda de un proyector las mismas imágenes que se encuentran en movimiento o estáticas, se adaptan de manera simbólica y literal al espacio físico. Existen una serie de conceptos clave que permiten analizar el video-mapping más allá de su condición técnica y nos ubican en un contexto más amplio a la imagen informática y más allá de su condición técnicas (representación numérica, modularidad, automatización, variabilidad y trans-codificación). Manovich, L. (2005). 
El uso del mapping es un método desarrollado para las actuaciones audiovisuales con el objetivo de crear mayor atención y simbolización ante la audiencia. Por ello este ejercicio nos ayuda a entender la dimensión del Video-Mapping corporal como práctica artística ligándose a las condiciones de la pedagógica de la imagen, de los medios materiales y de los entornos virtuales perceptibles en contenido artístico y educativo.

\section{Lecturas de la imagen virtual}

Esta práctica asume la siguiente pregunta; ¿Cuáles son las posibles lecturas de la imagen virtual en el espacio real?

Para realizar cualquier intervención artística sobre un espacio es necesario un análisis. El uso de la luz como materia plástica asume por controladas ciertas características físicas de la superficie a proyectar, contaminación lumínica, distancia de proyección y otros factores importantes en el uso de la imagen. Realizar un registro digital del espacio es esencial en el uso de estas técnicas y la reparación del entorno hacia la creación de un espacio híbrido entre lo virtual y lo real.

Esta práctica sólo es comprensible mediante la transformación del espacio físico como un modelo o una puerta a la virtualidad. El Video-Mapping corporal suma el uso de que las superficie a proyectar son personas y sus cuerpos.

Por esto la práctica resume una posible lectura de la técnica video-mapping como un método y dispositivo multiplicador que opera en el contexto de la educación artística entre la imagen real y virtual, la tecnologías basadas en el concepto de la virtualidad que puede ser entendidas como "un sistema que produce imágenes destinadas a ser experimentadas, según algunos, como más reales que lo real mismo" Maldonado (1999). Si a ello sumamos las aportaciones etnográficas de la práctica artística y la particularidad de interpretar los significados que aporta el contexto entre la comunidad que lo ejecuta, percibimos que esta técnica puede ser utilizada en muchos contextos educativos artísticos.

Ante la pedagogía de la imagen digital encontramos que uno de los grandes obstáculos es, como se concibió en la pintura, la fotografía y el cine: la bidimensionalidad. El diseño conceptual de las imágenes que se proyectan se desarrolla en un espacio diferente de lo que la obra de arte presentará. Desarrollar esta técnica como modelo pedagógico basado en la imagen virtual es enriquecedora. El cómo será mostrado el resultado en su entorno físico no es fiel al desarrollo conceptual. Solo la práctica en la técnica proporciona los detalles necesarios para crear un contenido artístico que valide los procesos y ser utilizadas como una herramienta entre la conexión de espacios físicos y virtuales para la aplicación de estructuras educativas novedosas y posibles en un práctica de la pedagogía de la imagen digital. La práctica de 
creación de imágenes virtuales basadas en Video-Mapping corporal aportan soluciones por uso en entornos virtuales principalmente actuando en dos frentes;

El primero sobre la representación misma y sobre la tecnología que utiliza. Es capaz de crear un espacio tridimensional donde en su forma fuera bidimensional. En el mismo camino son capaces de asociar la técnica con la enseñanza artística.

La máxima del medio se dispone como el mensaje centrado en el dominio de los artefactos a través de la mecanización de la imagen. El uso del mapping corporal supone la extensión de nuestro cuerpo gracias a ella hacia el espacio infinito, el cual es sustituido por a su vez un sin fin tecnológico de posibles creaciones virtuales.

Segundo por por las posibles potencialidades que da el uso de una imagen infinita.

La sinestesia que se produce la acción del cuerpo con la danza lumínica da origen a un contenido visual atractivo para los participantes.La imagen virtual ha heredado del cine la imagen-movimiento modificando sus características. Deleuze (1984)

La realización del contenido visual se realizó a través de un taller de fotografía monográfica. Se realizaron diferentes entrevistas que servirían como soporte conceptual para los modelos y en la proyección de imágenes virtuales.

A partir de estas entrevistas se estableció de manera directa una relación con elementos visuales de forma sinestésica que provocan una imagen mental abstracta proyectada y ayudaban a crear una conciencia virtual sobre la práctica antes de ejecutarla. Gracias a técnicas de creación de imagen virtual las representaciones visuales se integran en los diferentes actores para así ejercer formas diferentes de representación virtual.

El objetivo era encontrar una representación visual a la transmigración que cada bailarín/a sentía en su práctica escénica para vincular la imagen y así caracterizarla.

Las imágenes captadas mediante cámara fotográfica sufrieron transformaciones de profundidad, perspectiva, tono, luminosidad y se mezclaron los materiales con el objetivo de enriquecer la práctica entre participantes. Término ejecutándose una propuesta propicia a la traslación del espacio digital en el que se trabajaban las imágenes digitales y virtualizarlas llevándolas a un espacio que vinculaba luz, cuerpo y movimiento con resultados inesperados. 


\section{Resultados}

Los objetivos generales de la experiencia metodológicos y pedagógicos sobre la "Piel Virtual" en relación a la pedagogía de la imagen virtual y la indagación sobre las técnicas de proyección de la imagen a través de la técnica Video-Mapping corporal nos ayudaron a conocer las nociones básicas en la captación, almacenamiento, modificación de una imagen digital a través de en entorno virtual.

A su vez se estableció un marco común teórico en relación a la construcción de la imagen virtual en grupo de alumnos no relacionados directamente con la Educación Artística o las Artes Visuales.

Los talleres relacionados con la manipulación de las imágenes virtuales posee una potencialidad mimética corporal-expresiva en la relación entre el espacio real y virtual. Nos ayudan a comprender, a seleccionar imágenes y a crear composiciones útiles en el trabajo fotográfico y en la técnica fotográfica pues trabajan a su vez con diferentes formatos fotográficos y de vídeo. Son un mecanismo muy apropiado en la construcción de una identidad visual a partir de las imágenes que los propios modelos captan y transforman ,al modelo en artista y al artista en modelo. Y genera un marco común además de poseer ese efecto de sorpresa propio de los soportes digitales, creando retratos y un contenido audiovisual único.

Son en sí mismos, conectores de fuerzas ambientales que ayudan a generar un atmósfera creativa entre los participantes. Con estas condicionantes la imágenes virtuales actúan como materia en común de trabajo pues estas se pueden extender, integrar, diluir en su representación. Pero también se procesan, modifican y se transmiten para representar datos sensoriales. El análisis de la imagen se extrapola mutuamente entre lo real y lo virtual del espacio construido para el encuentro que atiende a la transcodificación constituye una traducción a otro formato del que no estamos tan familiarizados. Manovich, L. (2005).

Estas experiencias ayudan generando imágenes ilimitadas por otras composiciones no calificables sino experimentales por escalas, posiciones, proporciones y resoluciones. Con estas condicionantes la imágenes virtuales actúan como materia en común de trabajo pues estas se pueden extender, integrar, diluir en su representación también se procesan, modifican y se transmiten para representar datos sensoriales.Debido a la finalidad pedagógica que plantea estos enfoques basados en ABR se construye y proyectan representaciones de la realidad que enseñan otras formas de observar, definir y plantear un problema. Se considera que estas actividades de indagación relacionadas con la investigación artística contienen y muestran elementos en el diseño que afectan a la propia investigación, aunque en los procesos no estén expresamente reflejados en el resultado de la investigación. . Muntané, M. D. C. G., Hernández, F. H., \& López, H. J. P. (2006) 


\section{Referencias}

Belloch, C. (2012). Las Tecnologías de la Información y Comunicación en el aprendizaje. Departamento de Métodos de Investigación y Diagnóstico en Educación. Universidad de Valencia. https://www.uv.es/bellochc/pedagogia/EVA1.pdf

Biggs, M. (2003). The role of 'the work'in research. PARIP.

Deleuze, G. (1984). La imagen-movimiento. Barcelona: Paidós.

Maldonado, Tomás (1999). Lo real y lo virtual. España: editorial Gedisa https://issuu.com/claudiadanielaarayarivera/docs/lo real y lo virtual tomas maldon

Muntané, M. D. C. G., Hernández, F. H., \& López, H. J. P. (2006). Bases para un debate sobre investigación artística. Ministerio de Educación.

Marín-Viadel, R.; Roldán, J. (2019) A/r/tografía e Investigación Educativa Basada en Artes Visuales en el panorama de las metodologías de investigación en Educación Artística. Arte, Individuo y Sociedad 31(4), 881-895.

Manovich, L. (2005). El lenguaje de los nuevos medios. 
Revista de Estudios en Sociedad, Artes y Gestión Cultural

ISSN: $2340-9096$

https://dx.doi.org/10.17561/rtc.extra2.5750

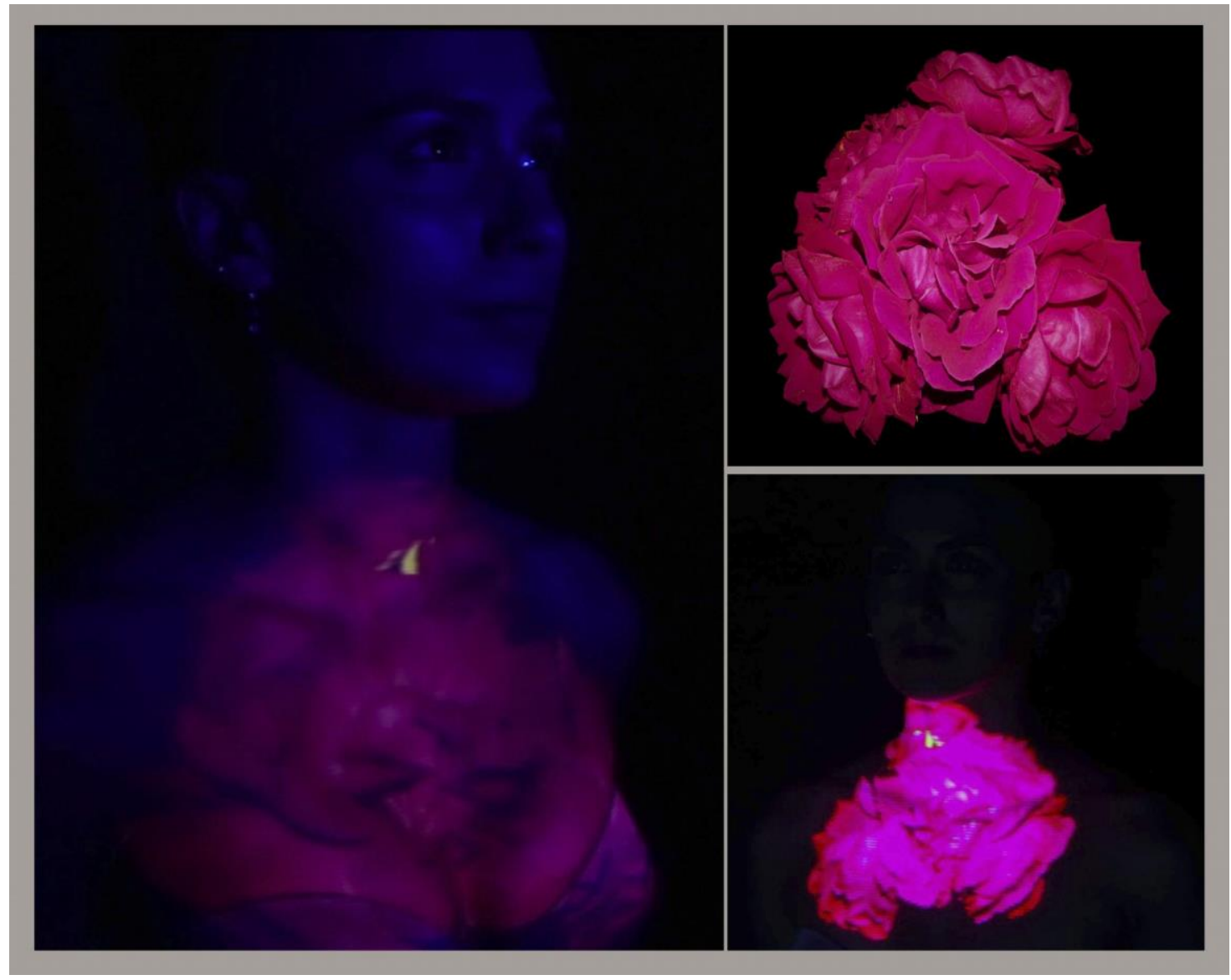

Antonio Gonzalez-Torre \& R.; Roldán, J. La Rosa (2020) 


\section{Tercio Creciente}

ISSN: $2340-9096$

https://dx.doi.org/10.17561/rtc.extra2.5750
Revista de Estudios en Sociedad, Artes y Gestión Cultural

Octubre 2020

Investigación

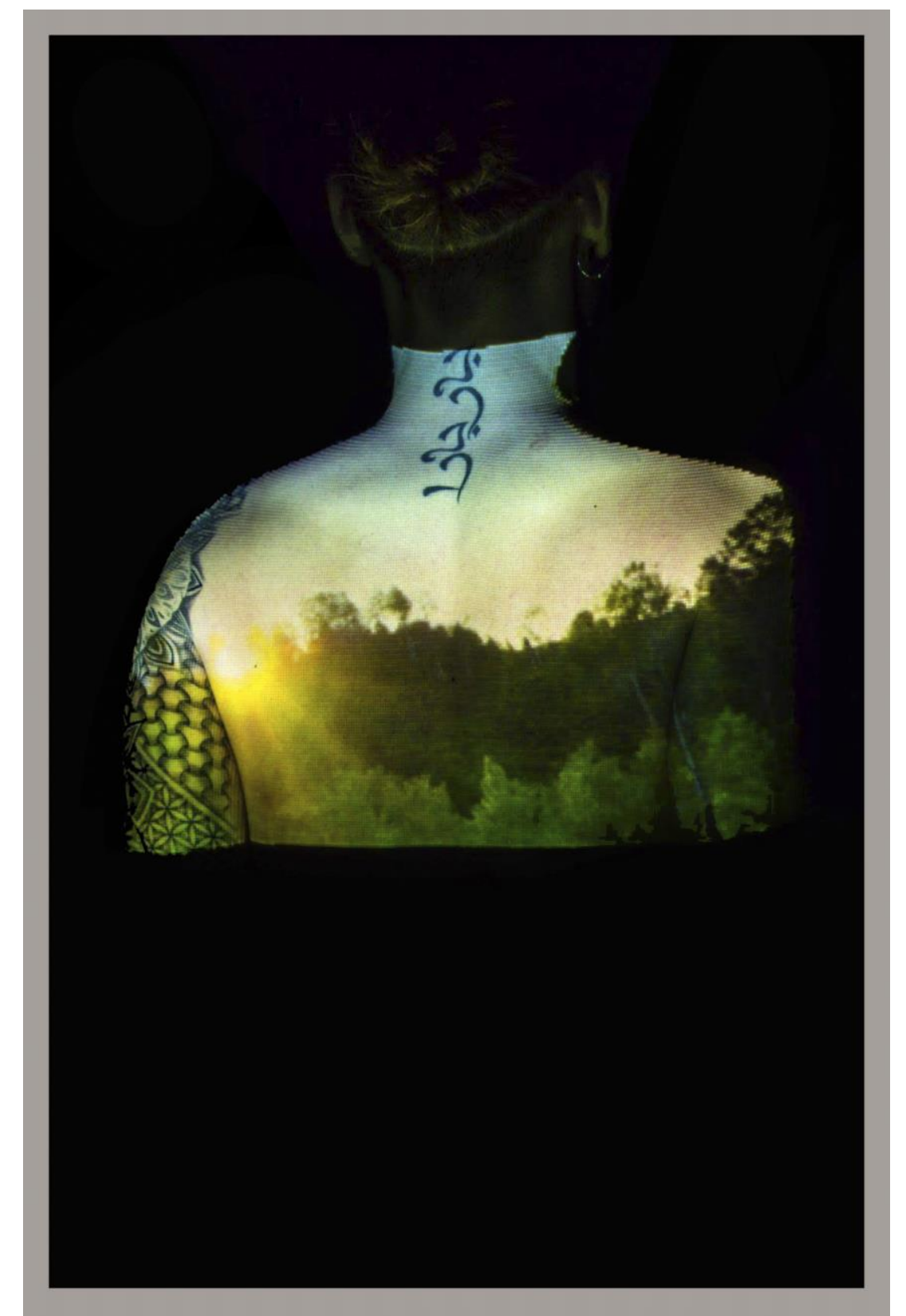

Antonio Gonzalez-Torre \& R.; Roldán, J. LandscapeSkin (2020) 


\section{Tercio Creciente}

ISSN: $2340-9096$

https://dx.doi.org/10.17561/rtc.extra2.5750
Investigación

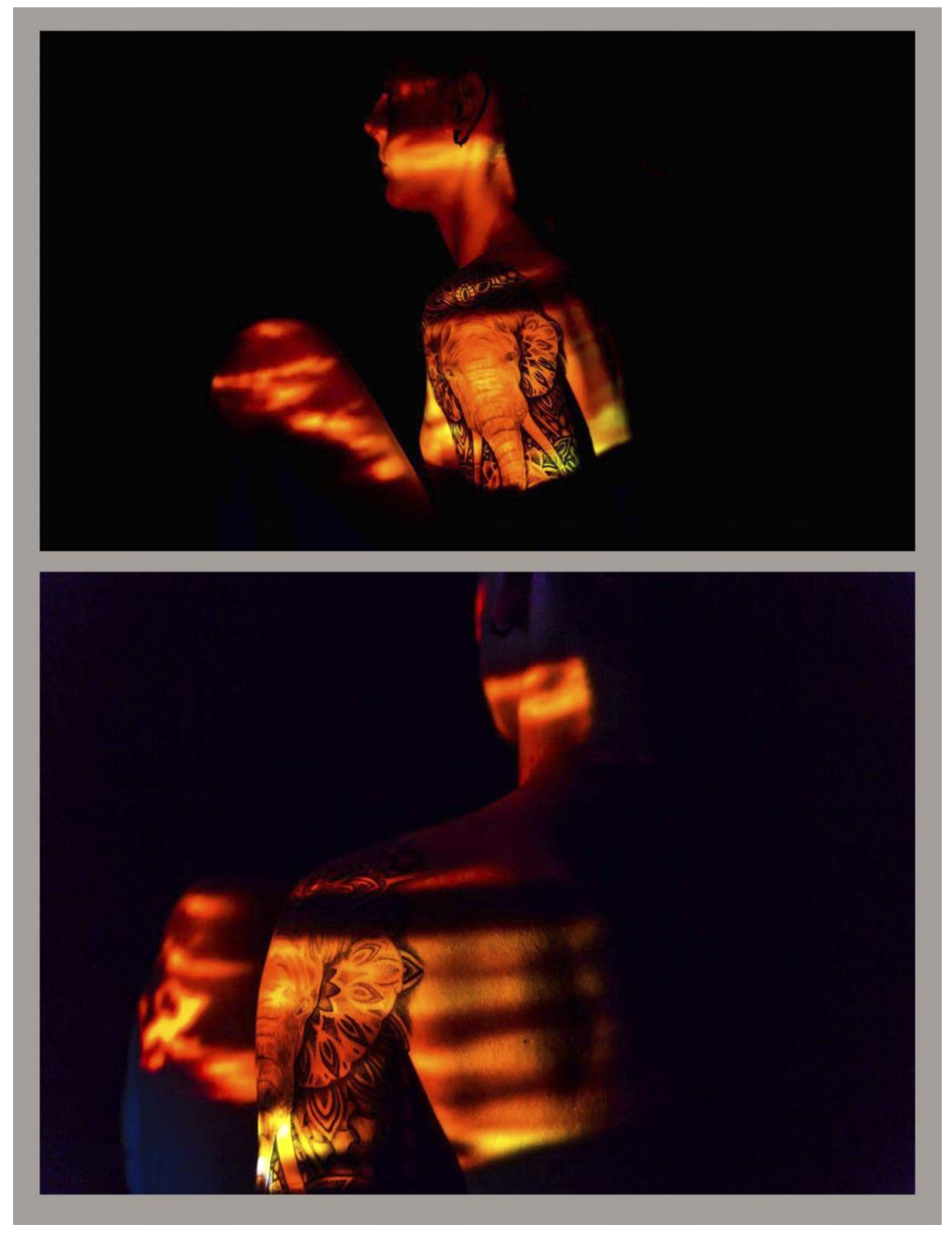

Antonio Gonzalez-Torre \& R.; Roldán, J. Sunrise (2020) 